\title{
Sex chromosome trisomies in Europe: prevalence, prenatal detection and outcome of pregnancy
}

\author{
Patricia Anne Boyd ${ }^{\star, 1}$, Maria Loane ${ }^{2}$, Ester Garne ${ }^{3}$, Babak Khoshnood ${ }^{4,5}$ and Helen Dolk ${ }^{2}$, a EUROCAT \\ working group ${ }^{6}$
}

This study aims to assess prevalence and pregnancy outcome for sex chromosome trisomies (SCTs) diagnosed prenatally or in the first year of life. Data held by the European Surveillance of Congenital Anomalies (EUROCAT) database on SCT cases delivered 2000-2005 from 19 population-based registries in 11 European countries covering 2.5 million births were analysed. Cases included were livebirths diagnosed to 1 year of age, fetal deaths from 20 weeks gestation and terminations of pregnancy for fetal anomaly (TOPFA). In all, 465 cases of SCT were diagnosed between 2000 and 2005, a prevalence of 1.88 per 10,000 births $(95 \% \mathrm{Cl} 1.71-2.06)$. Prevalence of $X X X, X X Y$ and $X Y Y$ were $0.54(95 \% \mathrm{Cl} 0.46-0.64), 1.04(95 \% \mathrm{Cl} 0.92-1.17)$ and $0.30(95 \% \mathrm{Cl} 0.24-0.38)$, respectively. In all, $415(89 \%)$ were prenatally diagnosed and $151(36 \%)$ of these resulted in TOPFA. There was wide country variation in prevalence $(0.19-5.36$ per 1000$)$, proportion prenatally diagnosed $(50-100 \%)$ and proportion of prenatally diagnosed resulting in TOPFA (13-67\%). Prevalence of prenatally diagnosed cases was higher in countries with high prenatal detection rates of Down syndrome. The EUROCAT prevalence rate for SCTs diagnosed prenatally or up to 1 year of age represents $12 \%$ of the prevalence expected from cytogenetic studies of newborn babies, as the majority of cases are never diagnosed or are diagnosed later in life. There is a wide variation between European countries in prevalence, prenatal detection and TOPFA proportions, related to differences in screening policies as well as organizational and cultural factors.

European Journal of Human Genetics (2011) 19, 231-234; doi:10.1038/ejhg.2010.148; published online 25 August 2010

Keywords: sex chromosome trisomies; prenatal diagnosis; termination of pregnancy

\section{INTRODUCTION}

Sex chromosome trisomies (SCTs; an extra X chromosome in females (triple $\mathrm{X}, \mathrm{XXX}$ ), males with an extra $\mathrm{X}$ chromosome, (Klinefelter syndrome, XXY) and males with an extra $\mathrm{Y}$ chromosome (XYY)), occur after an error during meiosis of the $\mathrm{X}$ or $\mathrm{Y}$ chromosome. Cytogenetic surveys of newborn infants carried out in the 1970's established incidence figures for each of the SCTs at around 1 in 1000 same sex individuals. ${ }^{1-3}$ A recent study reported that the prevalence of Klinefelter's syndrome is increasing. ${ }^{4}$

In contrast to the effect of an extra autosome, the effect of an extra sex chromosome is usually mild and most of the individuals born with one never get diagnosed. ${ }^{5,6}$ SCTs together represent the most common chromosome abnormalities compatible with live birth, a usually normal lifespan and few, if any dysmorphic features. Although major physical anomalies are not associated with SCTs, men with XXY are infertile. The relatively small amount of information available from population-based studies indicate that individuals with SCT are at increased risk of educational failure and neurodevelopmental disorder, with mean IQ broadly within the normal limits but reduced
10-20 points when compared with siblings; the biggest reduction in IQ being associated with XXX females. ${ }^{5,7-10}$

Some SCT cases are identified by chance prenatally when karyotyping is performed for different reasons, ${ }^{11}$ for example, after a higher risk Down's syndrome screening test. Parents are then faced with the knowledge that their baby has a condition about which there is a lack of information available from unbiased studies. After prenatal detection, parents receive information about the specific SCT from a variety of professionals and other sources. Some of the information given may be outdated, inaccurate and unduly negative because of the ascertainment bias inherent in small select populations in the studies of affected children. $^{7-9,11-13}$ Termination of pregnancy for fetal anomaly (TOPFA) is requested by some parents after prenatal diagnosis of a SCT. Rates of prenatal detection, information given to parents and differences in laws and practices regarding termination of pregnancy are some factors which may lead to differences in outcome. ${ }^{11-16}$

During the last decade, in many countries, there has been a move from offering only older mothers karyotyping to check for Down's syndrome, to offering all mothers first or second trimester screening

\footnotetext{
${ }^{1}$ National Perinatal Epidemiology Unit, University of Oxford, Oxford, UK; ${ }^{2}$ EUROCAT Central Registry, Institute of Nursing Research, University of Ulster, Ulster, UK; ${ }^{3}$ Paediatric Department, Hospital Lillebaelt, Kolding, Denmark; ${ }^{4}$ INSERM, UMR S953, Epidemiological Research Unit on Perinatal and Women's and Infant's Health, Paris, France; ${ }^{5}$ UPMC, Université Paris-6, Paris, France

${ }^{*}$ Correspondence: Dr PA Boyd, National Perinatal Epidemiology Unit, University of Oxford, Old Road Campus, Oxford OX3 7LF, UK. Tel: +44 1865 289 721 ; Fax: +44 1865289 701; E-mail: patricia.boyd@npeu.ox.ac.uk

6EUROCAT Working Group: Austria (Martin Häusler, Styria), Belgium (Christine Verellen-Dumoulin, Hainaut; Vera Nelen, Antwerp), Denmark (Ester Garne, Odense), France (Babak Khoshnood, Paris; Berenice Doray, Strasbourg), Germany (Simone Poetzsch, Saxony), Italy (Anna Pierini, Tuscany; Elisa Calzolari, Emilia-Romagna), Poland (Anna LatosBielenska, Wielkopolska), Portugal (Carlos Dias, South Portugal), Spain (Joaquin Salvador, Barcelona; Isabel Portillo, Basque Country), Switzerland (Marie-Claude Addor, Vaud), and England and Wales (Elizabeth Draper, East Midlands \& South Yorkshire; Judith Rankin, Northern England; Catherine Rounding, Thames Valley; David Tucker, Wales; Diana Wellesley, Wessex).

Received 12 February 2010; revised 21 June 2010; accepted 7 July 2010; published online 25 August 2010
} 
Table 1 Total number of births in EUROCAT registry areas in 2000-2005; number and prevalence of sex chromosomal trisomy cases, percentage prenatally diagnosed, median gestational age at diagnosis and percentage of prenatally diagnosed cases resulting in termination of pregnancy

\begin{tabular}{|c|c|c|c|c|c|c|c|}
\hline Country & EUROCAT register(s) & $\begin{array}{l}\text { Number of births in } \\
\text { EUROCAT registry } \\
\text { areas 2000-2005 }\end{array}$ & $\begin{array}{c}\text { Total cases sex } \\
\text { chromosome } \\
\text { trisomy }\end{array}$ & $\begin{array}{c}\text { Prevalence all sex } \\
\text { chromosomal trisomies } \\
\text { per } 10000 \text { births } \\
\text { (95\% confidence intervals) }\end{array}$ & $\begin{array}{c}\% \\
\text { Cases } \\
P D\end{array}$ & $\begin{array}{l}\text { Median } \\
\text { GA at } \\
\text { diagnosis }\end{array}$ & $\begin{array}{l}\% \text { Cases of } \\
P D \text { ending } \\
\text { in TOPFA }\end{array}$ \\
\hline Austria & Styria & 62667 & 8 & $1.28(0.64-2.55)$ & 100 & 15 & 13 \\
\hline Belgium & Antwerp, Hainaut & 182467 & 38 & $2.08(1.52-2.86)$ & 79 & 16 & 27 \\
\hline Denmark & Odense & 32003 & 5 & $1.56(0.65-3.75)$ & 60 & 11 & 67 \\
\hline England and Wales & $\begin{array}{l}\text { E Mid and S York, Northern England, } \\
\text { Thames Valley, Wales, Wessex }\end{array}$ & 951001 & 121 & $1.27(1.07-1.52)$ & 79 & 16 & 27 \\
\hline France & Paris, Strasbourg & 272618 & 84 & $3.08(2.49-3.82)$ & 98 & 17 & 38 \\
\hline Germany & Saxony-Anhalt & 106257 & 18 & 1.69 (1.07-2.69) & 78 & 15 & 43 \\
\hline Italy & Emilia Romagna, Tuscany & 343971 & 92 & $2.67(2.18-3.28)$ & 97 & 16 & 46 \\
\hline Poland & Wielkopolska & 206170 & 4 & $0.19(0.07-0.52)$ & 50 & 21 & 0 \\
\hline Portugal & Southern Portugal & 113310 & 18 & $1.59(1.00-2.52)$ & 100 & 18 & 44 \\
\hline Spain & Barcelona, Basque Country & 164864 & 54 & $3.28(2.51-4.28)$ & 95 & 16 & 44 \\
\hline Switzerland & Vaud & 42874 & 23 & $5.36(3.57-8.07)$ & 96 & 17 & 23 \\
\hline Total & & 2478202 & 465 & $1.88(1.71-2.06)$ & 89 & 16 & 36 \\
\hline
\end{tabular}

Abbreviations: E Mid, East Midlands; EUROCAT, European Surveillance of Congenital Anomalies; GA, gestational age; PD, prenatal diagnosis; S York, South Yorkshire; TOPFA, termination of pregnancy for fetal anomaly.

tests. ${ }^{16}$ Given the known association of XXX and XXY with maternal age, ${ }^{17}$ there may be a change in the prenatal detection rate of SCTs.

The European Surveillance of Congenital Anomalies (EUROCAT) is a network of population-based congenital anomaly registers in Europe which surveys more than 1.5 million births per year, and covers $29 \%$ of the annual European birth population. ${ }^{18}$ Full member registries of EUROCAT send anonymous case data on congenital anomalies including information on TOPFA in their region. One of the objectives of EUROCAT is to assess the impact of prenatal screening.

The aim of this paper is to provide a snapshot view of the occurrence of SCTs in Europe during the 6 years, 2000-2005 to enable monitoring of their prenatal detection and outcome of pregnancy as prenatal screening practices evolve. The specific objectives are to report the total prevalence of SCTs diagnosed up to 1 year of age in Europe; to describe the prevalence and proportion of prenatally diagnosed cases, gestational age (GA) at prenatal diagnosis and outcome of pregnancy of prenatally diagnosed cases and finally to relate the prevalence of prenatally diagnosed cases to the extent of prenatal karyotyping in the country (as indicated by the proportion of Down's syndrome cases detected prenatally, by maternal age).

\section{METHODS}

EUROCAT registries with GA at detection of a malformation known for at least $80 \%$ of SCTs for cases delivered between 2000 and 2005 were invited to participate in the study. Cases including livebirths, fetal deaths from 20 weeks gestation and those resulting in TOPFA after the prenatal diagnosis with a $47, \mathrm{XXX}, 47, \mathrm{XXY}$ or $47, \mathrm{XYY}$ karyotype and date of delivery or TOPFA from 2000 to 2005 inclusive, were extracted from the EUROCAT database. SCT cases diagnosed after 1 year of age or those with a mosaic karyotype were excluded. The upper age limit for reporting cases of congenital anomaly at registry level is at least 1 year of age and 15 of the 19 participating registries complied with this. Four registries (Barcelona, Emilia Romagna, Paris and South Portugal) limit postnatal registration to 3 days, 1 week, 1 week and 1 month, respectively.

The observed EUROCAT prevalence of SCTs was calculated and compared with that expected. Expected prevalence rates (5.0 per 10000 births for XXX and XYY and 6.3 for XXY) were obtained from published cytogenetic studies of consecutive newborns in the 1970 s. $^{1-3}$ Information on prenatal detection rates for Down's syndrome cases was extracted for the same registries and time period (2000-2005) to give a measure of the extent of prenatal karyotyping.

Variation in prevalence between countries was assessed using a $\chi^{2}$ test (STATA version 9.0, StataCorp LP, College Station, TX, USA).

\section{RESULTS}

In all, 19 EUROCAT Registries from 11 European countries agreed to take part in the study and fulfilled the entry criteria. There were approximately 2.5 million births in the registry areas (10\% of total births in the 11 countries) during the 6-year study period (Table 1) of which 465 were diagnosed as having a SCT before the age of 1 year. The overall prevalence of SCT was 1.88 per 10000 births (95\% CI $1.71-2.06)$, ranging from 0.19 (95\% CI 0.07-0.52) in Poland to 5.36 (95\% CI 3.57-8.07) in Switzerland (Table 1). A $\chi^{2}$ for heterogeneity test showed highly significant variation in prevalence of SCT between countries $(P<0.001)$.

A total of 415 cases $(89 \%)$ were diagnosed prenatally at a median gestation of 16 weeks, of which 151 (36\%) resulted in TOPFA (Table 1). The median GA at prenatal diagnosis varied between countries from 11 weeks in Denmark to 21 weeks in Poland (Table 1). There was significant variation in the proportion of prenatally diagnosed SCTs resulting in TOPFA between countries $(P<0.001)$.

Figure 1 shows the observed EUROCAT and expected prevalence ${ }^{1-3}$ of the three SCTs. The EUROCAT prevalence of XXX was 0.54 per 10000 births (95\% CI 0.46-0.64), of XXY was 1.04 per 10000 births (95\% CI 0.92-1.17) and of XYY was 0.30 per 10000 births (95\% CI 0.24-0.38). Overall, the EUROCAT prevalence of all SCTs combined represented $12 \%$ of the prevalence expected from cytogenetic studies of newborn babies. XXY had the highest EUROCAT or expected prevalence ratio (1.0: 6.3 per 10000 births), representing $17 \%$ of the expected prevalence.

Figure 2 shows the percentage of cases prenatally diagnosed and the percentage of prenatally diagnosed cases resulting in TOPFA for each SCT.

Overall, $41 \%$ of all SCTs prenatally diagnosed in mothers $<35$ years were terminated, though the proportion varied by type of SCT $(50 \%$ of XXX, $40 \%$ of XXY and 32\% of XYY). In contrast, 33\% of all SCTs prenatally diagnosed in mothers $\geq 35$ yearswere terminated $(23 \%$ of 


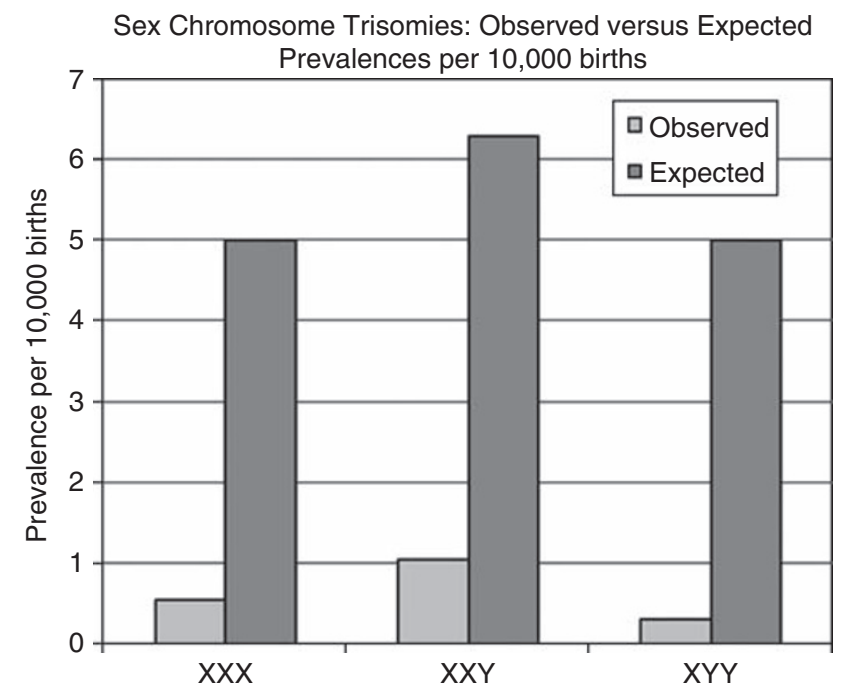

Figure 1 Observed and expected prevalence per 10000 births for sex chromosome trisomies, 2000-2005.

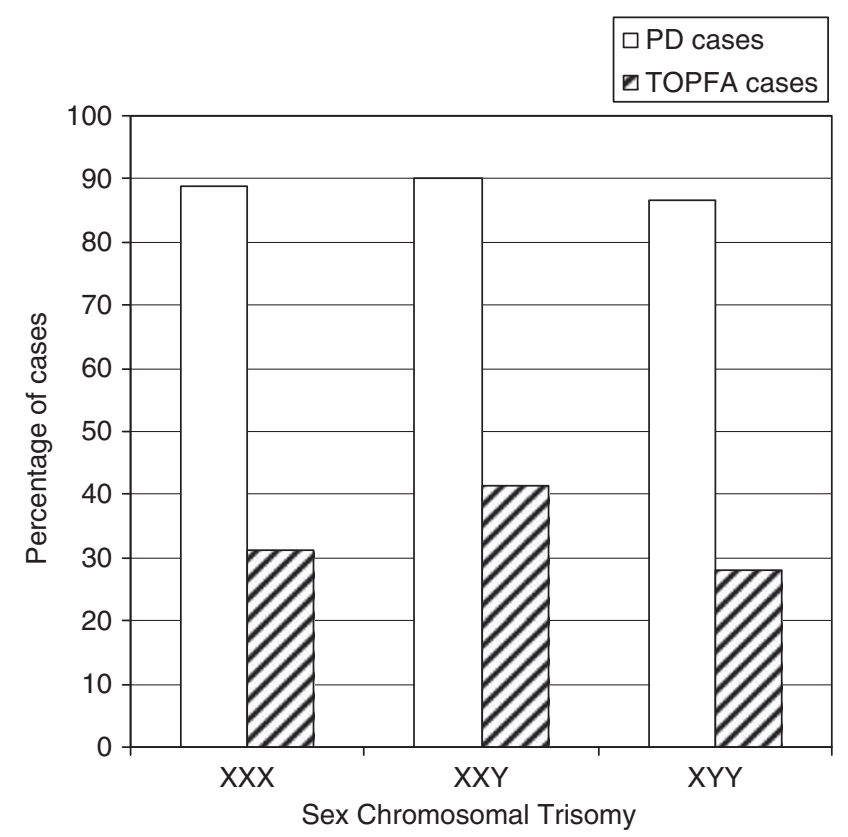

Figure 2 Percentage of sex trisomy cases prenatally diagnosed and the percentage of prenatally diagnosed cases resulting in termination of pregnancy for fetal anomaly, for each sex chromosome anomaly. PD, prenatal diagnosis.

XXX, $41 \%$ of XXY and $28 \%$ of XYY). The difference in proportion of termination rates performed for SCTs in under and over 35-year old mothers is statistically significance $(P=0.046)$.

Figure 3 shows the relationship between prevalence of prenatally diagnosed SCTs and the extent of prenatal karyotyping in the country (as indicated by the proportion of Down's syndrome cases detected prenatally), in mothers $\geq 35$ and those $<35,2000-2005$. In 7 out of 10 countries included in this analysis, $<60 \%$ of Down's syndrome cases in mothers $<35$ years were prenatally diagnosed. These seven countries have a corresponding low prevalence of prenatally diagnosed SCTs in mothers $<35$ years ( $<1$ per 10000 births). The three countries with the highest prenatal detection rate for Down's

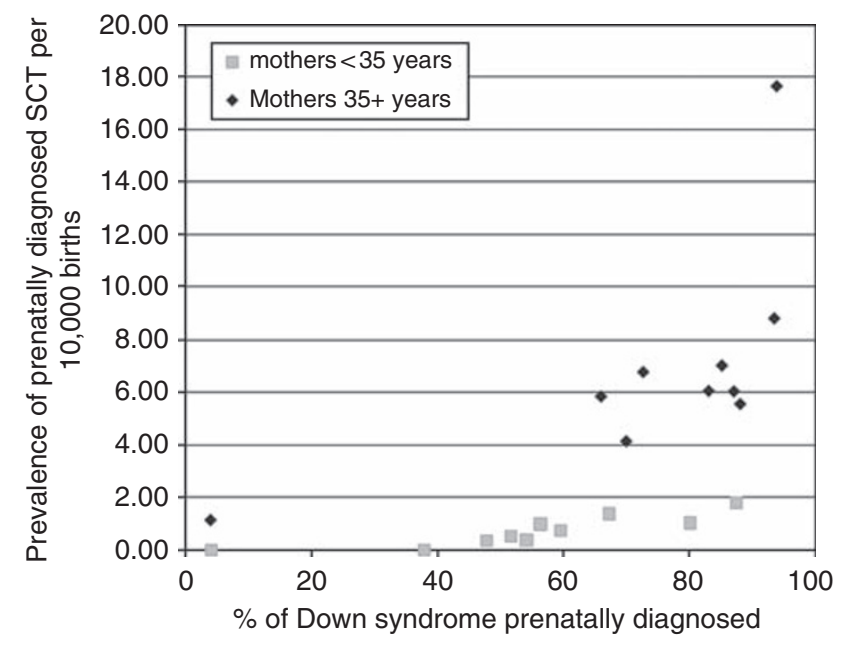

Figure 3 Relationship between prevalence of prenatally diagnosed sex chromosome trisomies and proportion of Down's syndrome cases detected prenatally. The percentages below are the percentage of Down's syndrome cases prenatally diagnosed and the prevalences cited are the prevalence of prenatally diagnosed sex chromosome trisomies per 10000 births. Mothers <35 years: Austria 54\%, 0.37; Belgium 52\%, 0.53; Denmark 38\%, 0.00; France 80\%, 1.03; Germany 60\%, 0.74; Italy 56\%, 0.98; Poland 4\%, 0.00; Spain 67\%, 1.38; Switzerland 88\%, 1.78; UK 48\%, 0.33. Mothers 35+ years: Austria 73\%, 6.79; Belgium 66\%, 5.86; Denmark 87\%, 6.05; France 94\%, 8.84; Germany 83\%, 6.07; Italy 85\%, 7.04; Poland 4\%, 1.14; Spain 88\%, 5.57; Switzerland 94\%, 17.67; UK 70\%, 4.15. Analysis based on 17 out of 19 registries-Hainaut (Belgium) and South Portugal were excluded as maternal age denominators available for $<80 \%$ of the population.

syndrome in mothers aged $<35$ years (France, Spain and Switzerland)) have a higher prevalence of SCT in this age group (range 1.03-1.78 per 10000 births). In Poland, where 4\% of Down's syndrome cases were prenatally detected in mothers $35+$ years, the prevalence of SCTs among older mothers was 1.14 per 10000 . In all countries except Poland, $>60 \%$ of Down's syndrome cases were detected in mothers $35+$ years, and prevalence of prenatally diagnosed SCT ranged from 4.15 per 10000 births to 17.67 per 10000 births.

\section{DISCUSSION}

SCTs represent an important and often neglected group of anomalies. It is well established that most individuals with SCTs never get diagnosed and that many of those that do are due to chance rather than because of a suspicion of the extra sex chromosome. ${ }^{6}$ The reason for the high prenatal diagnosis rate for SCTs described in this study is because only those diagnosed before 1 year of age are included and most get diagnosed because of the prenatal karyotyping performed because of advanced maternal age or as a result of a Down's syndrome screening test.

This study showed a prevalence of SCTs diagnosed prenatally or in the first year of life of 1.88 per 10000 birth, representing approximately $12 \%$ of the expected prevalence. The expected prevalence was based on the studies of newborns infants carried out in the 1970s, in which every newborn was karyotyped at the time of birth. Given that currently there are a higher proportion of older mothers than in the 1970s, and the risk for XXX and XXY increases with maternal age, ${ }^{17}$ the expected prevalence given is probably an underestimate for our population. It was not possible for us to estimate meaningful agespecific prevalence, as the chances of prenatal detection varies by age.

Abramsky and Chapple ${ }^{6}$ studied numbers of XXY and XYY males diagnosed pre- or postnatally during the 4 years between 1990 and 
1993, and compared them with the numbers expected from cytogenetic surveys. Regarding XXY males, they estimated that approximately $12 \%$ were diagnosed prenatally and a further $1 \%$ postnatally under 1 year of age, none between 1 and 10 years, 7\% between 11 and 20 years and $19 \%$ at more than 20 years - a total of $12 \%$ diagnosed prenatally and $27 \%$ diagnosed postnatally. Regarding the XYY cases, approximately $5 \%$ were diagnosed prenatally and $12 \%$ postnatally ( $1 \%$ under 1 year, $5 \%$ between 1 and 20 years and $6 \%$ at more than 20 years). The higher percentage of XXY than XYY cases diagnosed prenatally reflects the association with maternal age ${ }^{17}$ and postnatally the associated infertility leading to karyotyping in the $>20$ age group. This study shows a higher percentage of the expected cases being diagnosed for XXY males (17\% compared with $13 \%$ up to 1 year of age), possibly because of an increase in prenatal karyotyping. As XYY is not associated with maternal age, it is not surprising that both studies report a low prenatal detection rate for this SCT.

We found that the proportion of the expected cases diagnosed was higher for XXY than for XXX and XYY in the EUROCAT data. Given that $\mathrm{XXX}$ is strongly related to the maternal age, $\mathrm{XXY}$ has some relationship and XYY no relationship, ${ }^{17}$ that average maternal age has gone up since the newborn cytogenetic surveys, and that the prenatal karyotyping rate is greater among older mothers, we would have predicted a higher proportion of expected cases for XXX rather than XXY. Our contrary result may reflect a feature of XXY that increases the chance for prenatal detection, or that the true prevalence has increased. ${ }^{4}$

The wide variation in observed prevalence, in the proportion of cases prenatally diagnosed, and in the proportion of those that are electively terminated found in this and other studies, ${ }^{19}$ reflects at least in part, the variation across European registries in the availability of prenatal screening (ultrasound and antenatal screening for Down's syndrome) as well as organizational and cultural factors. ${ }^{16}$ We found that although prevalence of prenatally diagnosed SCTs was clearly broadly related to the prenatal detection rate of Down Syndrome, there was still considerable further variation. For example, Switzerland had a particularly high rate of prenatally diagnosed SCTs among older mothers. This may reflect variation between countries in the extent to which amniocentesis and CVS are preceded by screening tests in older mothers, which reduce the rate of invasive tests in this age group. Although the majority of SCTs detected prenatally would be because of the karyotyping performed because of advanced maternal age or a higher risk Down's syndrome screening test, some may have been because of suspicion of abnormality on prenatal ultrasound scan and details of these scans are not available in our study.

This study provides baseline data on prenatal detection and prevalence rates of SCTs, which will enable the monitoring of changes in screening practices, affecting the detection of SCTs. The increasing use of screening tests for Down's syndrome such as the first trimester combined test, offered to women of any age, to identify those at high risk has led to a reduction in the diagnostic test rate in some centres ${ }^{20}$ and this is likely to be reflected in a lower detection rate of SCTs in the future. The introduction of noninvasive prenatal diagnosis in the future $^{21}$ means that it would be feasible to test for SCTs in all pregnancies. Whether SCTs should be included or excluded in the diagnostic tests performed and what the advantages and disadvantages would be are complex and controversial.

This study found that $36 \%$ of prenatally diagnosed SCTs result in TOPFA. A declining trend in TOPFA for SCTs has been reported. ${ }^{12-15}$ Whether this reflects more positive counseling from health professionals or a better understanding of the sex chromosome condition is not known. The significantly higher termination rate for XXX cases in mothers aged $<35$ compared with those $>35$ years in this study is difficult to explain. Whether there is an advantage in diagnosing SCTs prenatally when the aim of the prenatal screening test is to detect Down's syndrome is debatable. Parents are faced with difficult information and decisions. For those that continue the pregnancy forewarning of potential learning and behavioral difficulties ${ }^{10}$ may allow early intervention and support.

The importance of providing parents with accurate information about the frequency of the diagnosis and the variability of the condition on the basis of outcomes from unbiased population-based follow-up studies on the specific chromosome abnormality cannot be over emphasized. ${ }^{5}$

\section{CONFLICT OF INTEREST}

The authors declare no conflict of interest.

\section{DISCLAIMER}

This paper reports on an independent study which is part funded (Thames Valley, UK) by the Policy Research Programme in the Department of Health. The views expressed are not necessarily those of the Department.

1 Jacobs PA, Melville M, Ratcliffe S, Keay AJ, Syme J: A cytogenetic survey of 11680 newborn infants. Ann Hum Genet 1974; 37: 359-376.

2 Hamerton JL, Canning N, Ray M, Smith S: A cytogenetic study of 14069 newborn infants. Clin Genet 1975; 8: 223-243.

3 Nielsen J, Sillesen I: Incidence of chromosome aberrations among 11148 newborn children. Humangenetik 1975; 30: 1-12.

4 Morris JK, Alberman E, Scott C, Jacobs P: Is the prevalence of Klinefelter syndrome increasing? Eur J Hum Genet 2008; 16: 163-170.

5 Ratcliffe S: Long term outcome in children of sex chromosome abnormalities. Arch Dis Child 1999; 80: 192-195.

6 Abramsky L, Chapple J: 47,XXY (Klinefelter syndrome) and 47,XYY: estimated rates and indication for postnatal diagnosis with implications for prenatal counseling. Prenatal Diagnosis 1997; 17: 363-368.

7 Linden MG, Bender BG, Robinson A: Genetic counseling for sex chromosome abnormalities. Am J Med Genet 2002; 110: 3-10.

8 Leggett V, Jacobs P, Nation K, Scerif G, Bishop DVM: Neurocognitive outcomes of individuals with a sex chromosome trisomy: XXX, XYY or XXYA systematic review. Dev Med Ch Neurol 2010; 52: 119-129.

9 Otter M, Schrander-Stumpel CTRM, Curfs LMG: Triple $X$ syndrome: a review of the literature. Eur J Hum Genet 2009; 18: 265-271.

10 Bishop DV, Jacobs PA, Lachlan $\mathrm{K}$ et al: Autism spectrum disorders, language and communication in children with sex chromosome trisomies. Arch Dis Child 2010, e-pub ahead of print 23 July 2010.

11 Abramsky L, Hall S, Levitan J, Marteau TM: What parents are told after prenatal diagnosis of a sex chromosome abnormality: interview and questionnaire study. BMJ 2001; 322: 463-466.

12 Forrester MB, Merz RD: Pregnancy outcome and prenatal diagnosis of sex chromosome abnormalities in Hawaii, 1986-1999. Am J Med Genet Part A 2003; 199: 305-310.

13 Marteau TM, Nippert I, Hall S et al: Outcomes of pregnancies diagnosed with Klinefelter syndrome: the possible influence of health professionals. Prenat Diagn 2002; 22: 562-566.

14 Brun JL, Gangbo F, Wen ZQ et al: Prenatal diagnosis and management of sex trisomy aneuploidy: a report of 98 cases. Prenat Diagn 2004; 24: 213-218.

15 Mezei G, Papp C, Toth-Pal E, Beke A, Papp Z: Factors influencing parental decision in prenatal diagnosis of sex chromosome aneuploidy. Obstet Gynecol 2004; 104: 94-101.

16 Boyd PA, DeVigan C, Khoshnood B, Loane M, Garne E, Dolk H, The EUROCAT Working Group: Survey of prenatal screening policies in Europe for structural malformations and chromosome anomalies, and their impact on detection and termination rates for neural tube defects and Down's syndrome. BJOG 2008; 115: 689-696.

17 Ferguson-Smith MA, Yates JRW: Maternal age specific rates for chromosome aberrations and factors influencing them: report of a collaborative European study on 52965 amniocenteses. Prenat Diagn 1984; 4: 5-44.

18 EUROCAT, http://www eurocat-network eu.

19 Garne E, Khoshnood B, Loane M, Boyd P, Dolk H, EUROCAT working group: Termination of pregnancy for fetal anomaly after 23 weeks of gestation: a European registerbased study. BJOG 2010; 117: 660-666.

20 Ekelund CK, Jorgensen FS, Petersen OB, Sundberg K, Tabor A, Danish Fetal Medicine Research Group: Impact of a new national screening policy for Down's syndrome in Denmark: population based cohort study. BMJ 2008; 337: a2547.

21 Lo YM: Non-invasive prenatal detection of fetal chromosomal aneuploidies by maternal plasma nucleic acid analysis: a review of the current state of the art. BJOG 2009; 116: 152-157. 